\title{
Targeting mTOR signaling overcomes acquired resistance to combined BRAF and MEK inhibition in BRAF-mutant melanoma
}

\author{
Beike Wang ${ }^{1,11}$, Wei Zhang ${ }^{1,11}$, Gao Zhang $\mathbb{D}^{2,10,11}$, Lawrence Kwong ${ }^{3}$, Hezhe Lu ${ }^{4}$, Jiufeng Tan $^{2}$, Norah Sadek ${ }^{2}$, Min Xiao ${ }^{2}$, Jie Zhang $\mathbb{D D}^{5}$, \\ Marilyne Labrie $\mathbb{1 0}^{6}$, Sergio Randell ${ }^{2}$, Aurelie Beroard ${ }^{2}$, Eric Sugarman $\mathbb{1}^{2}$, Vito W. Rebecca ${ }^{2}$, Zhi Wei ${ }^{5}$, Yiling Lu' ${ }^{7}$, Gordon B. Mills (10 ${ }^{6}$,

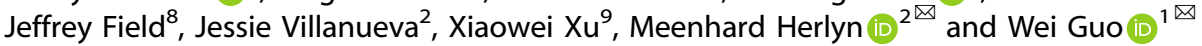

(c) The Author(s) 2021

Targeting MAPK pathway using a combination of BRAF and MEK inhibitors is an efficient strategy to treat melanoma harboring BRAF-mutation. The development of acquired resistance is inevitable due to the signaling pathway rewiring. Combining western blotting, immunohistochemistry, and reverse phase protein array (RPPA), we aim to understanding the role of the mTORC1 signaling pathway, a center node of intracellular signaling network, in mediating drug resistance of $B R A F-$ mutant melanoma to the combination of BRAF inhibitor (BRAFi) and MEK inhibitor (MEKi) therapy. The mTORC1 signaling pathway is initially suppressed by BRAFi and MEKi combination in melanoma but rebounds overtime after tumors acquire resistance to the combination therapy (CR) as assayed in cultured cells and PDX models. In vitro experiments showed that a subset of CR melanoma cells was sensitive to mTORC1 inhibition. The mTOR inhibitors, rapamycin and NVP-BEZ235, induced cell cycle arrest and apoptosis in CR cell lines. As a proof-of-principle, we demonstrated that rapamycin and NVP-BEZ235 treatment reduced tumor growth in CR xenograft models. Mechanistically, AKT or ERK contributes to the activation of mTORC1 in CR cells, depending on PTEN status of these cells. Our study reveals that mTOR activation is essential for drug resistance of melanoma to MAPK inhibitors, and provides insight into the rewiring of the signaling networks in CR melanoma.

Oncogene (2021) 40:5590-5599; https://doi.org/10.1038/s41388-021-01911-5

\section{INTRODUCTION}

Metastatic melanoma is the most aggressive form of skin cancer [1]. Approximately $50 \%$ of cutaneous melanomas harbor activating BRAF mutations, which drive hyperactivation of the MitogenActivated Protein Kinase (MAPK) signaling pathway [2, 3]. Targeting MAPK pathway using a combination of BRAF and MEK inhibitors elicits a $70 \%$ response rate in patients with BRAF-mutant melanoma [4-6]. Additionally, adjuvant use of BRAF/MEK inhibitors resulted in a lower risk of relapse in patients with stage III melanoma [4]. Despite the encouraging observations, the development of acquired resistance is almost inevitable, limiting the efficacy and duration of these targeted therapies. Dynamic rewiring of signaling networks allows tumor cells to adapt to the BRAF and MEK inhibitors treatment. Molecular mechanisms that underlie acquired resistance to BRAF inhibitor monotherapy can be attributed to the reactivation of ERK, activating mutations in NRAS, alternative activation of RTK-mediated pathways, amplification or truncation of $B R A F$, overexpression of COT, mutations in MEK1 and other genetic events [5-10]. In terms of resistance to BRAFi and MEKi combination therapy (CR), several mechanisms including the development of MEK2 mutations, acquisition of concurrent BRAF/NRAS mutations, amplification of $B R A F$, ER translocation of the ERK and others have been reported [11-16]. In addition, MAPK-independent mechanisms such as the rewiring of RAC1/CDC42-PAK signaling pathway [17], alternative activation of the PI3K/AKT signaling axis [15], and immune-related components in tumor microenvironments also contribute to $C R$ [18].

mTOR is a conserved serine and threonine protein kinase that plays a critical role in cell growth by regulating transcription, protein synthesis, ribosome biogenesis, and cell metabolism [19-24]. mTOR kinase acts in two functionally distinct complexes, mTOR complex 1 (mTORC1) and 2 (mTORC2), whose activities and substrate specificities are regulated by their co-factors [25-27]. Aberrant mTOR activation has been observed in many types of cancers including metastatic melanoma [28-33]. mTORC1 and mTORC2 activity is regulated by the PI3K pathway in response to growth factors and cell stress stimuli [34-38]. In addition,

\footnotetext{
${ }^{1}$ Department of Biology, School of Arts \& Sciences, University of Pennsylvania, Philadelphia, PA, USA. ${ }^{2}$ Molecular and Cellular Oncogenesis Program and Melanoma Research

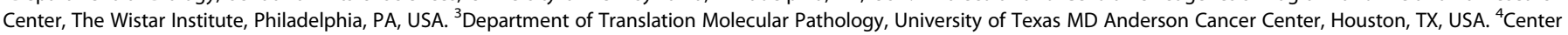

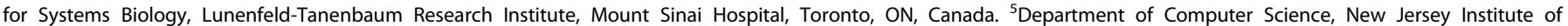

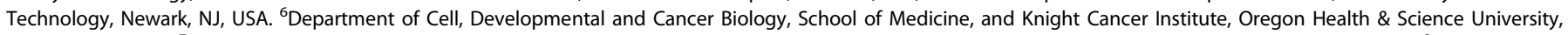

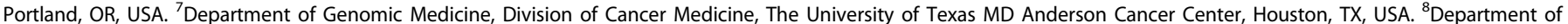

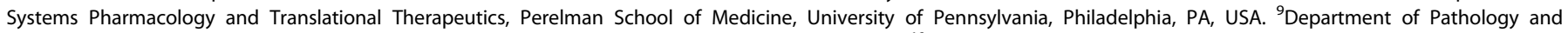

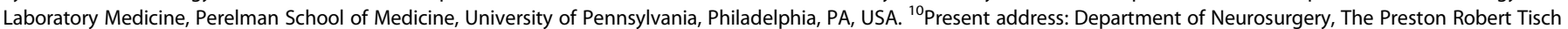
Brain Tumor Center and Department of Pathology, Duke University Medical Center, Durham, NC, USA. ${ }^{11}$ These authors contributed equally: Beike Wang, Wei Zhang, Gao Zhang. 凶email: herlynm@wistar.org; guowei@sas.upenn.edu
} 
activation of ERK also leads to increased mTOR activity in mTORC1 through TSC2 phosphorylation [39]. Since both the MAPK/ERK and PI3K/AKT signaling pathways converge into mTORC1, this signaling pathway may be crucial for the efficacy of targeted therapy in patients with BRAF-mutant melanoma. Decreased mTORC1 activity following MAPK inhibition has been shown to be necessary for the induction of apoptosis and cell cycle arrest in melanoma cells [40]. Resistance to BRAF or MEK inhibitors is also associated with the adaptive induction or persistence of the activation of the AKT pathway [41, 42], an upstream regulator of mTORC1. Resistance could also be reversed by inhibiting PI3K [43-45].

In this study, we have systematically studied mTORC1 signaling in different subsets of established BRAF-mutant melanoma cells that acquired resistance to combined BRAF and MEK inhibition. We show that mTORC1 reactivation plays a pivotal role in development of CR. The activation of mTORC1 requires ERK or AKT, depending on PTEN status of the tumors. We further show that the recovery of mTORC1 activity represents a therapeutic vulnerability for CR BRAF-mutant melanoma. mTOR inhibitors significantly inhibited proliferation and induced apoptosis of $C R$ cells. Our study provides a molecular mechanism by which BRAFmutant melanoma cells gain resistance to BRAFi and MEKi combination therapy, and implicates mTOR inhibition for further treatment of CR patients.

\section{RESULTS}

mTORC1 activity is restored in melanoma cells resistant to BRAFi/MEKi combination

To better understand the effect of combined BRAFi and MEKi on resistance-associated $\mathrm{mTORC1}$ signaling, we treated a panel of paired parental and CR BRAF mutant melanoma cell lines with PLX4720 (PLX, $2.5 \mu \mathrm{M}, \mathrm{BRAFi}$ ) and PD0325901 (PD, $0.25 \mu \mathrm{M}, \mathrm{MEKi})$ for $24 \mathrm{~h}$ (Fig. 1). Of these cell lines, A2058, UACC903, and WM9 are BRAF mutant cells with homozygous PTEN loss; 1205Lu has heterozygous PTEN loss; A375 and WM164 are cell lines with wild-type PTEN [46-49]. Our assay confirmed the loss of PTEN in A2058, UACC903, and WM9, and expression in A375 and WM164 melanoma cells. PTEN was barely detectable in $1205 \mathrm{Lu}$ cells, despite its heterozygous loss of PTEN. Expression of p-ERK (T202/ Y204) was decreased in parental cells with the combined BRAF and MEK inhibition, but was unchanged or only slightly decreased in CR melanoma cell lines after the same treatment. The BRAFi and MEKi combination markedly reduced $\mathrm{p}-\mathrm{S} 6^{\mathrm{S240/244}}$ and $\mathrm{p}-\mathrm{P} 70-\mathrm{S} 6 \mathrm{~K}^{\mathrm{T} 389}$

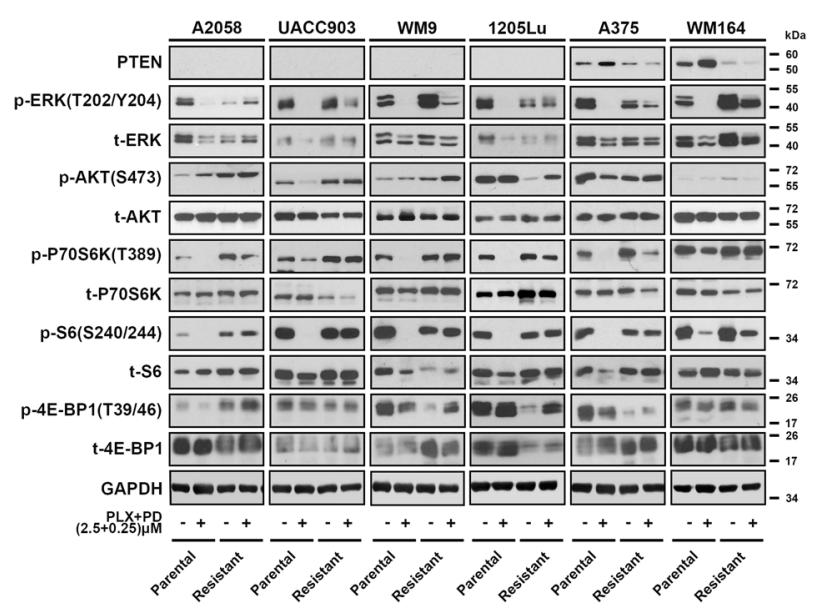

Fig. 1 Recovery of mTORC1 activity in CR melanoma cell lines. Western blot analysis showing the phosphorylation levels of proteins associated with mTORC1 and AKT signaling pathways in parental and CR melanoma cells. Data are representative of three independent biological experiments. levels in parental cells, but recovered in CR cells. Since both $\mathrm{p}$ $\mathrm{S} 6^{\mathrm{S} 240 / 244}$ and $\mathrm{p}-\mathrm{P} 70-\mathrm{S} 6 \mathrm{~K}^{\mathrm{T} 389}$ are direct downstream components of mTORC1 signaling, these results suggest that mTORC1 signaling was initially suppressed by combined BRAF and MEK inhibition, but later rebounded upon gaining resistance. Phosphorylation of another mTORC1 downstream molecule, 4EBP1, did not appear to be inhibited by the combined BRAFi and MEKi in either parental or CR cells. This may be attributed to the complicated array of upstream regulators for 4EBP1 such as p53, PI3K, and ATM [50]. Additionally, phosphorylation of AKT was increased in the CR cells with PTEN loss, suggesting that adaptive induction of PI3K/AKT signaling pathway could contribute to the survival of CR cells. We noted that, in parental cells with wild-type PTEN, combined BRAF and MEK inhibition increased the expression of PTEN. Similar observation was reported in melanoma cells treated with MEK inhibitor [51].

mTORC1 activity in CR melanoma xenograft and PDX models Next, we examined mTORC1 signaling in xenografts of paired parental and CR melanoma cell lines as well as patient-derived xenograft models. To test our hypothesis that mTORC1 activity was initially suppressed during short-term MAPKi and rebounded after long-term treatment, we examined $1205 \mathrm{Lu}$ xenografts and WM3929 PDX tumors that were untreated (denoted as "Pre"), short-term treated with BRAF and MEK inhibitors (denoted as "On$\left.t^{\prime \prime}\right)$, or a long-term treated until resistance arose (denoted as "Resistance"). Tumor growth was substantially inhibited upon the short-term treatment with the BRAF and MEK inhibitor combination (On-tx group), and the tumors gradually progressed after 60 days of treatment (Resistance group), suggesting $C R$ was successfully established in these cells (Fig. 2A, B). To determine if mTORC1 activity was restored in CR tumors, we examined the levels of S6 phosphorylation, and Ki67 as a marker of proliferation. We found that p-S6 ${ }^{\text {S240/244 }}$ and Ki67 levels were inhibited in both 1205Lu xenografts and WM3929-PDX tumors during the shortterm treatment but restored in the $C R$ xenografts (Fig. $2 C, D$ ), indicating that the mTORC1 signaling is reactivated in $C R$ melanoma in vivo. We asked whether there was any difference in baseline level of $\mathrm{p}$ - $\mathrm{S} 6$ between parental and $\mathrm{CR}$ xenografts. Immunohistochemistry (IHC) staining of p-S6 ${ }^{\text {S240/244 }}$ and Ki67 was performed in paired A375, WM164, WM9, A2058, UACC903 parental and CR xenografts and WM4237.1 parental and CR PDX (Fig. 2E). Ki67 expression was not obviously different in four out of six of the paired parental and $C R$ xenografts, suggesting that $C R$ xenografts have similar proliferative ability as their parental counterpart. The levels of $p-S 6$ in A375-CR, WM164-CR, UACC903-CR, and WM4237.1 CR-PDX xenografts were comparable to their parental counterparts, suggesting mTORC1 signaling in CR xenografts recovered to baseline levels after development of resistance.

\section{mTOR inhibition induces cell cycle arrest and inhibits CR cell proliferation}

To test whether inhibition of mTORC1 could overcome resistance to combined BRAF and MEK inhibition, we used rapamycin, an allosteric mTORC1 inhibitor. We also included in our experiments NVP-BEZ235 (BEZ235), a dual PI3K and mTOR inhibitor [52]. For cell viability detection, both rapamycin and BEZ235 sensitized CR cells to combined BRAF and MEK inhibition (Fig. 3A, Figs. S1 and S2A, B). BEZ235 alone showed inhibitory effect on the growth of CR cells, and the inhibitory effect was further enhanced in most cells when combined with BRAF and MEK inhibitors. Rapamycin alone did not show obvious inhibitory effects (Fig. S1). We next performed reverse phase protein array (RPPA) on two of the cell lines, A2058CR and UACC903-CR (Fig. 3B). The TSC/mTOR signaling pathway and cell cycle progression were downregulated in both A2058-CR and UACC903-CR cell lines, accompanied by increased apoptosis. Western blotting analysis showed that rapamycin decreased the 


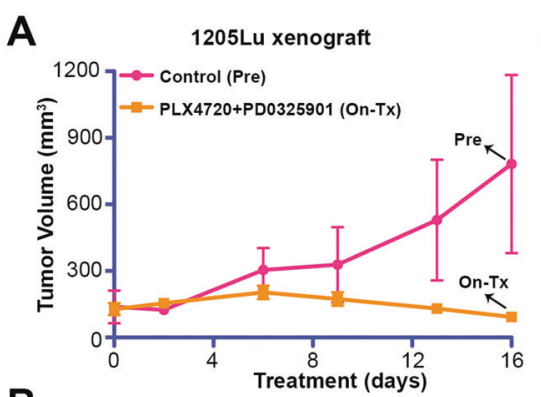

B

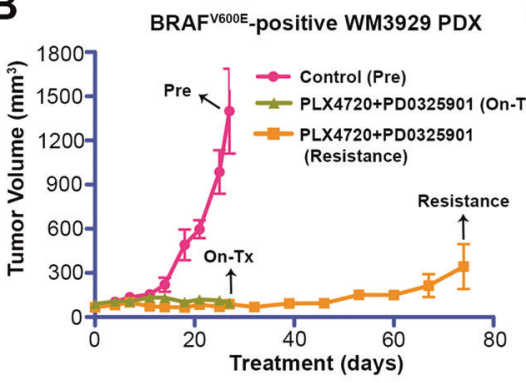

C

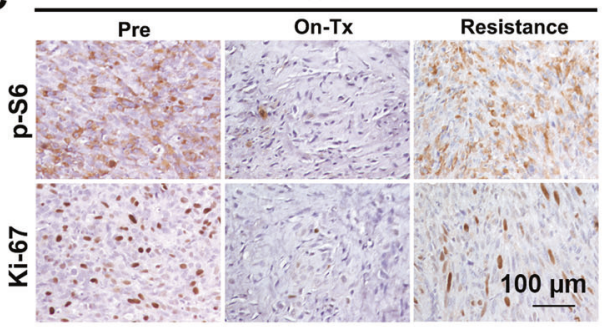

D

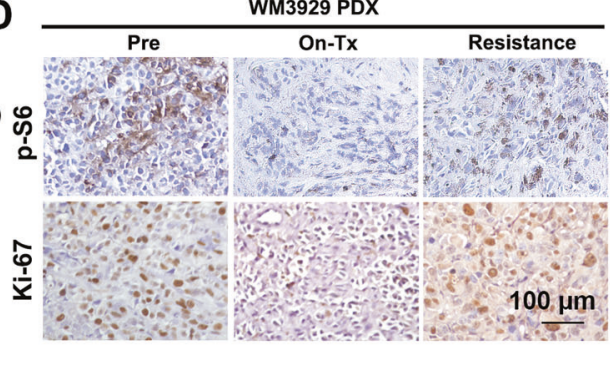

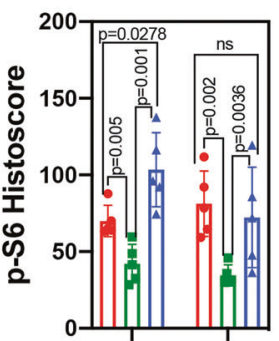

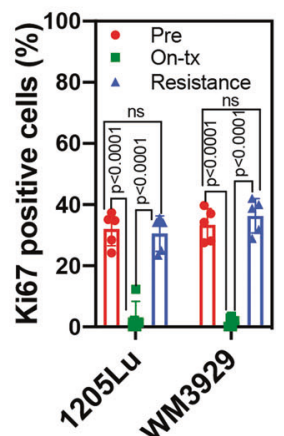

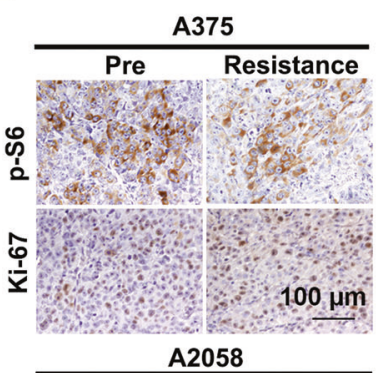
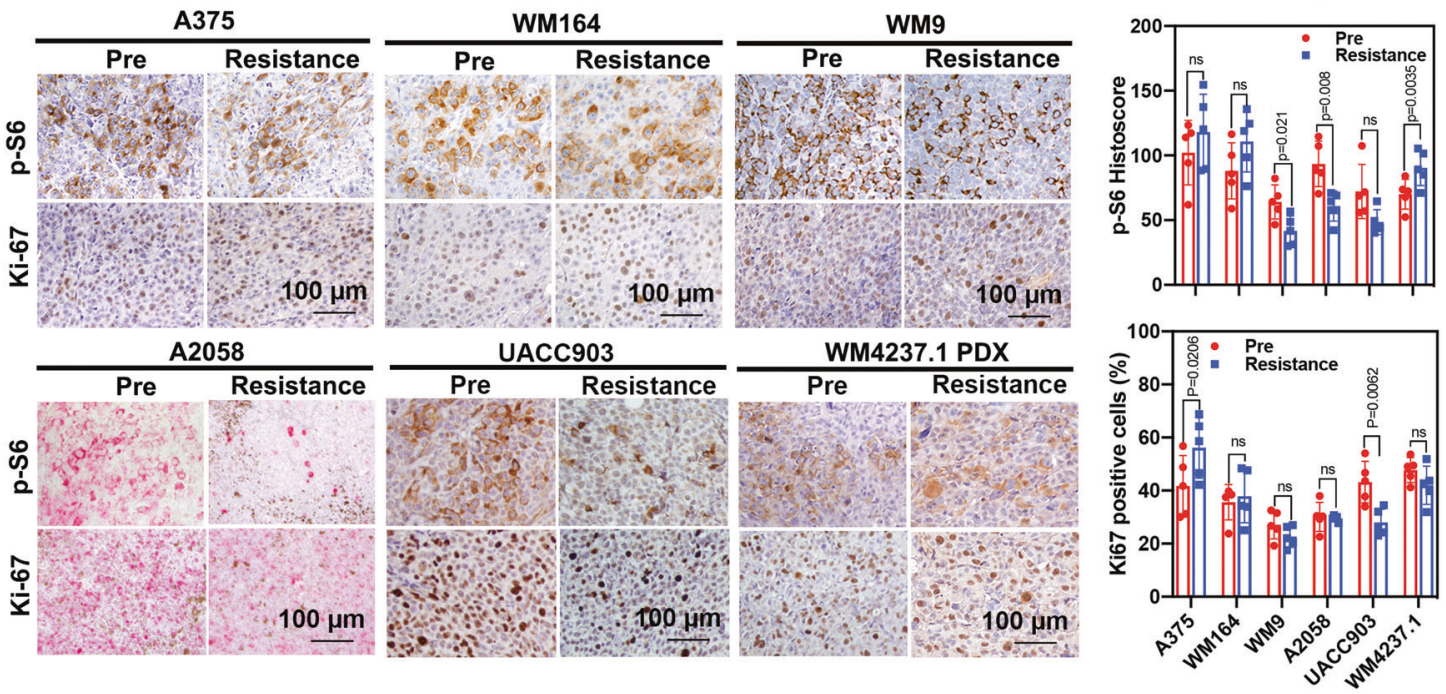

Fig. 2 Restoration of mTORC1 activity in CR melanoma xenografts and PDXs. Tumor growth curve of 1205Lu xenografts (A) and WM3929 PDX (B) before treatment ("Pre"), with short-term treatment ("On-Tx") and relapsed after long-term treatment ("Resistance") with combined BRAF and MEK inhibitors, $n=5$ mice for each indicated group. Black arrows represent the time points of sample collection. Representative IHC (left) and quantification (right) of p-S6 and Ki-67 staining of the 1205Lu xenograft (C) and WM3929 PDX (D) tumors. The $\mathrm{H}$-score of IHC images for each mouse ( $n=5$ mice per group) were quantified from five high-power fields. E Representative IHC images (left) and quantification (right) of $\mathrm{p}-\mathrm{S} 6$ and $\mathrm{Ki}-67$ staining in the melanoma xenograft tumors. Data are presented as mean \pm SD. $P$ values are based on a two-sided unpaired Student's $t$-test.

levels of $\mathrm{p}-\mathrm{P} 70-\mathrm{S} 6 \mathrm{~K}^{\mathrm{T} 389}$ and $\mathrm{p}-\mathrm{S} 6^{\mathrm{S} 240 / 244}$ in CR cells (Fig. $3 \mathrm{C}$ and Fig. S3). As a dual PI3K-mTOR inhibitor, BEZ235 also inhibited the phosphorylation of AKT in all PTEN loss CR cells, whereas rapamycin increased the p-AKT level in A2058-CR cells and did not change the p-AKT level in UACC903-CR and WM9-CR cells (Fig. S3). BEZ235 also inhibited the phosphorylation of P70-S6K, S6, and $4 \mathrm{E}-\mathrm{BP} 1$ in $\mathrm{CR}$ cell lines, consistent with the inhibition of both mTORC1 and PI3K. Both rapamycin and NVP-BEZ235 downregulated cell cycle-related proteins such as $\mathrm{p}-\mathrm{Rb}$ and cyclin $\mathrm{B} 1$ and the anti-apoptotic protein $\mathrm{BCl}-\mathrm{xL}$ in these CR cell lines (Fig. $3 \mathrm{C}$ ). Rapamycin induced moderate apoptosis in some cells, whereas BEZ235 induced much stronger apoptosis. Similar observation was made in a previous study demonstrating that rapamycin combined with PI3K inhibitor could induce marked cell death in the de novo resistant melanoma cell lines to PLX4720 by blocking AKT phosphorylation [53]. We further analyzed the effect of mTOR inhibition on proliferation rate, cell cycle progression, and induction of apoptosis in these CR cells. Rapamycin significantly reduced the percentage of EdU-positive cells in WM164-CR (Rapa vs. Control: $17.24 \pm 2.20 \%$ vs. $30.14 \pm 11.8 \%, P<0.05)$, UACC903-CR (Rapa vs. Control: $6.10 \pm 2.581 \%$ vs. $16.25 \pm 7.1 \%, P<0.05$ ) and A2058-CR (Rapa vs. Control: $12.21 \pm 2.870 \%$ vs. $19.21 \pm 6.0 \%, P<$ $0.05)$ cells, while BEZ235 almost completely inhibited cell proliferation in WM164-CR, UACC903-CR and A2058-CR cells (Fig. $3 \mathrm{D}$ and Fig. S2C). Flow cytometry analysis showed that rapamycin and BEZ235 led to an increase of CR cells in $G_{1}$ phase. In addition, $B E Z 235$ led to an increase in the percentage of cells in sub- $G_{1}$ phase, consistent with BEZ235 inducing apoptosis in CR melanoma cells $(P<0.01$ in WM164-CR and A2058-CR, $P<0.05$ in UACC903CR) (Fig. 3E). We also analyzed the effect of combination treatment using Annexin-V/7-AAD double staining. Rapamycin led to a moderate induction of apoptosis, while BEZ235 induced apoptosis 
A

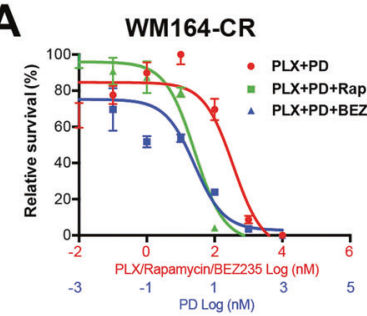

B

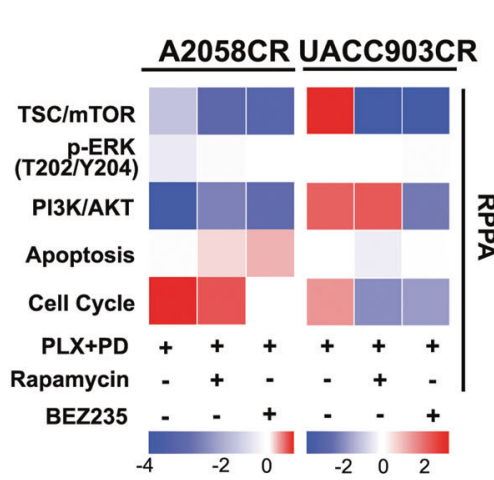

D
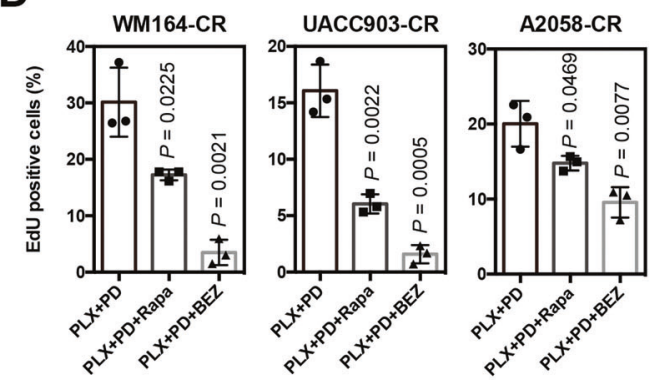

E
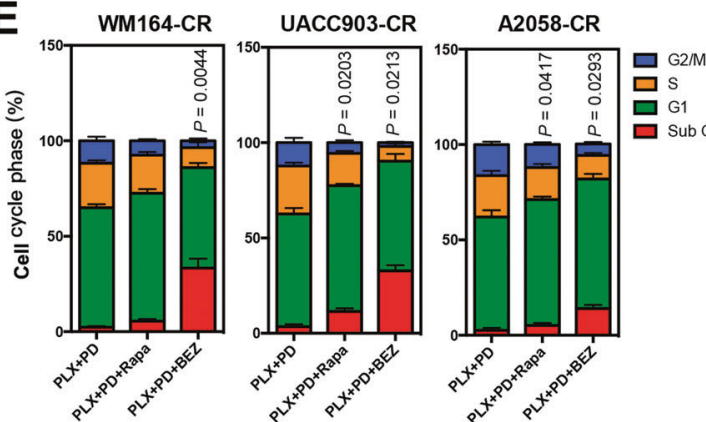

A2058-CR

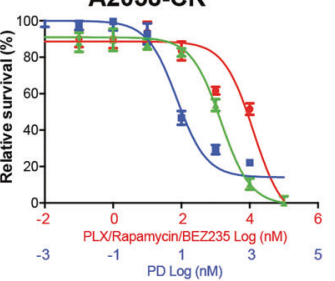

C

p-Rb (S807/811)

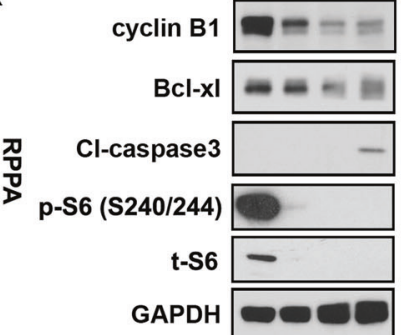

PLX + PD - + +

Rapamycin

BEZ235
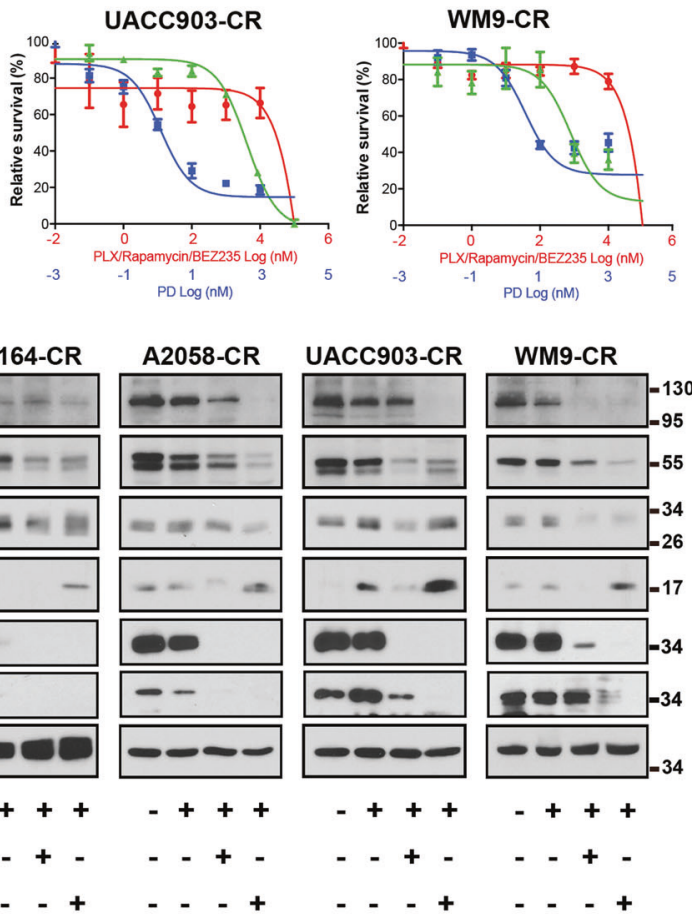

F
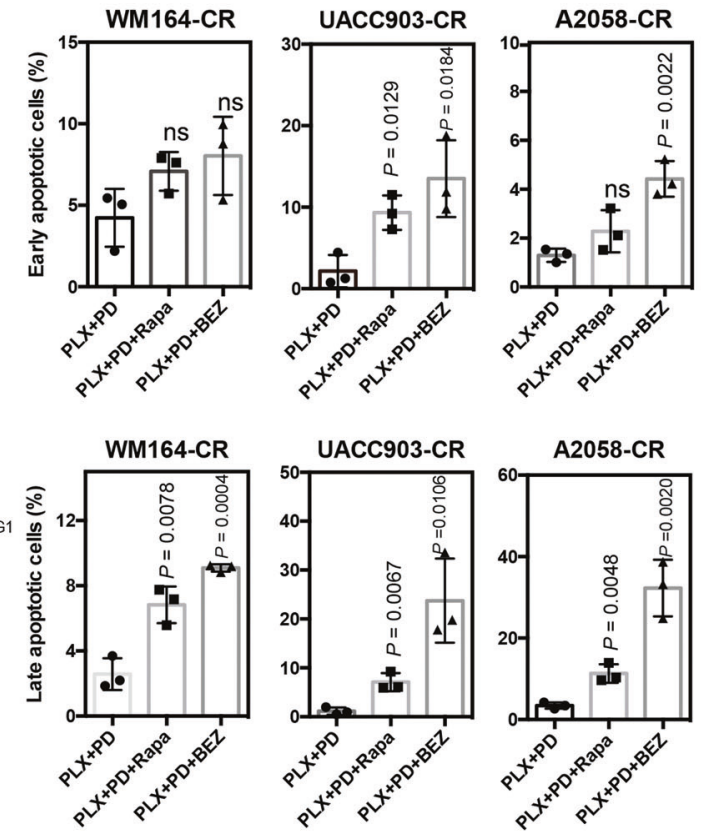

Fig. 3 mTOR inhibitors induce cell cycle arrest and apoptosis in CR melanoma cells. A Relative survival of WM164-CR, A2058-CR, UACC903$C R$, and WM9-CR cells treated with increasing concentrations of Rapamycin (Rapa, Max = $100 \mu \mathrm{M}), \mathrm{NVP}-\mathrm{BEZ235}(\mathrm{BEZ}, \mathrm{Max}=100 \mu \mathrm{M}), \mathrm{PLX} 4720$ $(P L X, M a x=100 \mu \mathrm{M})$ and PD0325901 (PD, Max =10 $\mu \mathrm{M})$ for $72 \mathrm{~h}$. B Heatmaps of indicated pathway scores from RPPA analysis of A2058-CR and UACC903-CR cells after treatment with PLX $(2.5 \mu \mathrm{M})+$ PD $(0.25 \mu \mathrm{M})$ in the absence or presence of Rapa $(100 \mathrm{nM})$ and BEZ $(1 \mu \mathrm{M})$ for $24 \mathrm{~h}$. C The expression of cell cycle and apoptosis -related proteins was analyzed by western blotting in CR cells treated with indicated inhibitors (PLX, $2.5 \mu \mathrm{M} ; \mathrm{PD}, 0.25 \mu \mathrm{M}$; Rapa, $100 \mathrm{nM}$; BEZ, $1 \mu \mathrm{M})$ for $72 \mathrm{~h}$. D Quantification of EdU incorporation assays performed to detect the proliferation of WM164-CR, UACC903-CR, and A2058-CR melanoma cells treated with Rapamycin (Rapa, $100 \mathrm{nM}$ ) and NVP-BEZ235 (BEZ, $1 \mu \mathrm{M})$ in the presence of PLX $(2.5 \mu \mathrm{M})$ and PD $(0.25 \mu \mathrm{M})$ for $24 \mathrm{~h}$. E Flow cytometry analysis of cell cycle stages of cells in (D). F Quantification of early and late apoptotic cell population treated with Rapamycin and NVP-BEZ235 in the presence of BRAF and MEK inhibitors by the Annexin V/7-AAD double staining. Data are presented as mean \pm SD $(n=3)$. $P$ values (vs. PLX + PD treatment group) are from a two-sided unpaired Student's $t-$ test.

in these three $C R$ melanoma cell lines $(P<0.01$ in WM164-CR and A2058-CR, $P<0.05$ in UACC903-CR) (Fig. 3F and Fig. S2D). This is consistent with a previous study showing that MEK $1 / 2$ and a PI3K/ mTOR inhibitor was more effective in the activation of Bax and caspase- 3 and in the induction of caspase-dependent apoptosis [54].

To evaluate the effect of mTOR inhibitors in vivo, we treated A2058-CR and UACC903-CR xenograft tumors with BRAF and MEK 
A

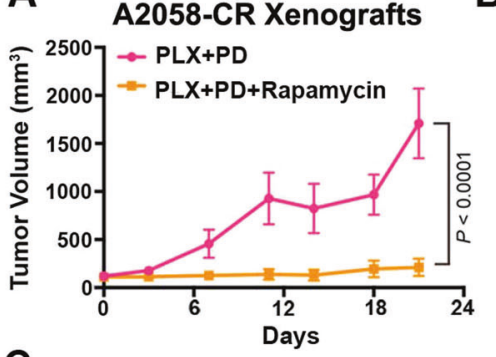

C

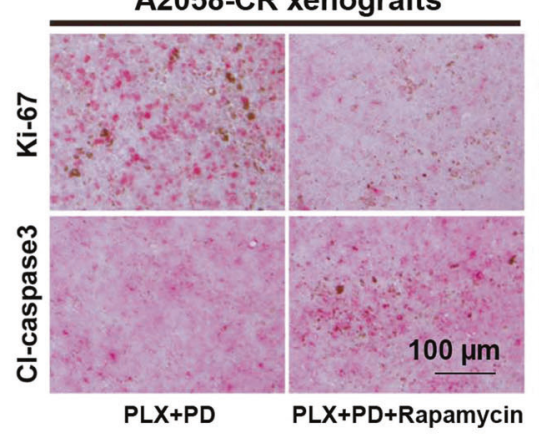

B

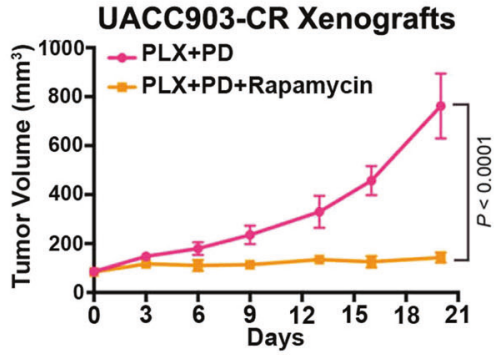

UACC903-CR xenografts

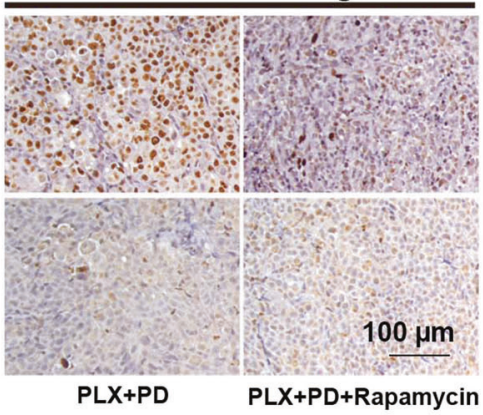

D

A2058-CR xenografts
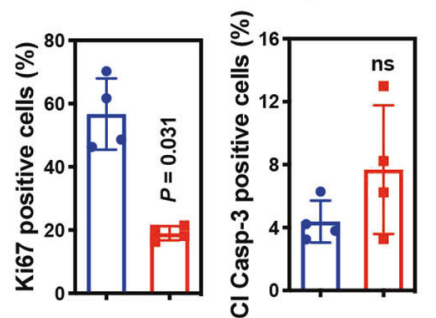

UACC903-CR xenografts
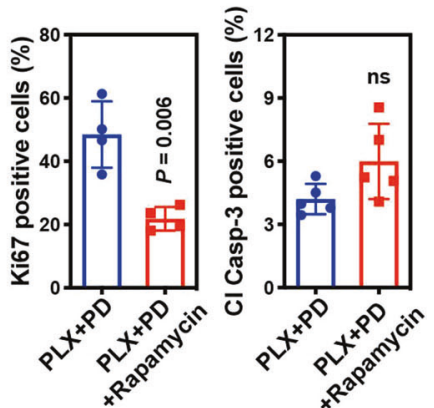

Fig. 4 Rapamycin suppresses the growth of CR melanoma xenograft tumors. Tumor growth curve of A2058-CR xenografts (A) and UACC903-CR xenografts (B) treated with rapamycin in the presence of PLX4720 and PD0325901, $n=5$ mice for each indicated group. C Representative Ki67 and cleaved caspase-3 IHC images in the xenografts treated with vehicle or rapamycin in the presence of PLX4720 and PD0325901. D Quantification of Ki67 and cleaved caspase-3 in the tumors. The indicated molecular of positive expression level for each mouse $(n=4$ mice per group) were quantified from 5 high-power fields. Data are presented as mean \pm SD. $P$ values are from a two-sided unpaired Student's $t$-test.

inhibitors together with rapamycin or BEZ235. The addition of rapamycin or BEZ235 inhibited tumor growth for both A2058-CR and UACC903-CR xenografts (Fig. 4A, B; Figs. S4 and S5A, B). Analysis of the treated tumors by IHC staining showed a substantial decrease in the percentage of Ki67 positive cells in both A2058-CR and UACC903-CR tumors after combined treatment with rapamycin, PLX-4720, and PD0325901 (Fig. 4C, D). However, consistent with the in vitro data, the percentage of cleaved caspase- 3 positive cells were not significantly changed, suggesting that rapamycin did not elicit obvious apoptosis in CR xenografts. Taken together, our results provide a rationale to inhibit mTORC1 activity to overcome acquired resistance to combined BRAF/MEK inhibitors.

\section{Contribution of PI3K/AKT and ERK to mTORC1 activity in CR cells}

We next sought to understand the molecular mechanism underlying the recovery of mTORC1 activity in melanoma cells in the context of acquired resistance to the BRAFi and MEKi combination. Since MAPK and AKT signaling pathways stimulate mTORC1 activity, we treated $\mathrm{CR}$ cells with either the ERK inhibitor, SCH772984, or the AKT inhibitor, MK-2206, in addition to the BRAFi and MEKi combination. In cell lines with complete PTEN loss (A2058-CR, UACC903-CR, and WM9-CR), SCH-772984 did not downregulate $\mathrm{p}-\mathrm{S} 6^{\mathrm{S240/244}}$ or $\mathrm{p}-4 \mathrm{E}-\mathrm{BP} 1^{\mathrm{T37} / 46}$, suggesting that the activity of mTORC1 in these CR cells is independent on the MAPK pathway (Fig. 5A). In contrast, MK-2206 significantly suppressed the expression of $\mathrm{p}-\mathrm{S} 6^{\mathrm{S240/244}}$ and $\mathrm{p}-4 \mathrm{E}-\mathrm{BP} 1^{\mathrm{T37} / 46}$ in these cell lines, suggesting that mTORC1 activity was dependent on AKT activity. In PTEN ${ }^{+/-}$or PTEN ${ }^{+/+}$cells (1205Lu-CR, A375-CR, and WM164-CR cells), however, both SCH-772984 and MK-2206 suppressed the levels of $\mathrm{p}-\mathrm{S} 6$ and $\mathrm{p}-4 \mathrm{E}-\mathrm{BP} 1$ (Fig. 5A), suggesting that mTOR signaling in these cell lines was regulated by both AKT and ERK signaling. Next, we examined whether inhibition of AKT or ERK changes the growth of CR melanoma cells. MK-2206 significantly impaired the viability of the PTEN ${ }^{-1-}$ cells (A2058-CR, UACC903$C R$, and WM9-CR), while the ERK inhibitor had a limited effect (Fig. 5B, C). Both AKT and ERK inhibitors significantly decreased the viability of $1205 \mathrm{Lu}-\mathrm{CR}\left(P T E N^{+/-}\right)$, while ERK inhibitors were more effective for WM164-CR and A375-CR cells $\left(P T E N^{+/+}\right)$. These results suggest that the differential sensitivity of CR cells to AKT vs. ERK inhibition depends on their PTEN status. Based on our results, a model illustrating the different contributions of MAPK and PI3K/ AKT to mTOR-mediated CR is presented in Fig. 6.

\section{DISCUSSION}

The major challenge of targeted therapy for treating metastatic melanoma is acquired drug resistance [7, 9, 55-57]. Our previous study underscored the importance of signaling network rewiring in the acquisition of drug resistance to combined BRAF and MEK inhibitors in metastatic melanoma [17]. In the current study, we focused on mTORC1 because it is a nexus targeted by upstream signals such as PI3K pathway and MAPK pathway [58]. Recently, several mTOR inhibitors have been approved by the U.S. Food and Drug Administration to treat different types of cancers $[59,60]$. However, whether and how mTORC1 activation contributes to acquired resistance of combined BRAF and MEK inhibition, and whether mTOR inhibitors have a therapeutic benefit through overcoming combined therapy resistance remain elusive.

Previous studies have examined the role of mTOR signaling in naive melanoma cell lines with de novo resistance or acquired resistance to BRAFi or MEKi $[9,40,51,53,61,62]$. Taking advantage of an array of CR cell lines and xenografts, we now present evidence for a crucial role of mTORC1 in BRAF-mutant CR melanoma. We observed the restoration of mTORC1 activity in $\mathrm{CR}$ cells. In addition to BRAF mutant melanoma, enhanced mTORC1 activity has also been reported to associate with acquired resistance to combined inhibition of CDK4/6 and MEK in NRASmutant melanomas [63]. 
A

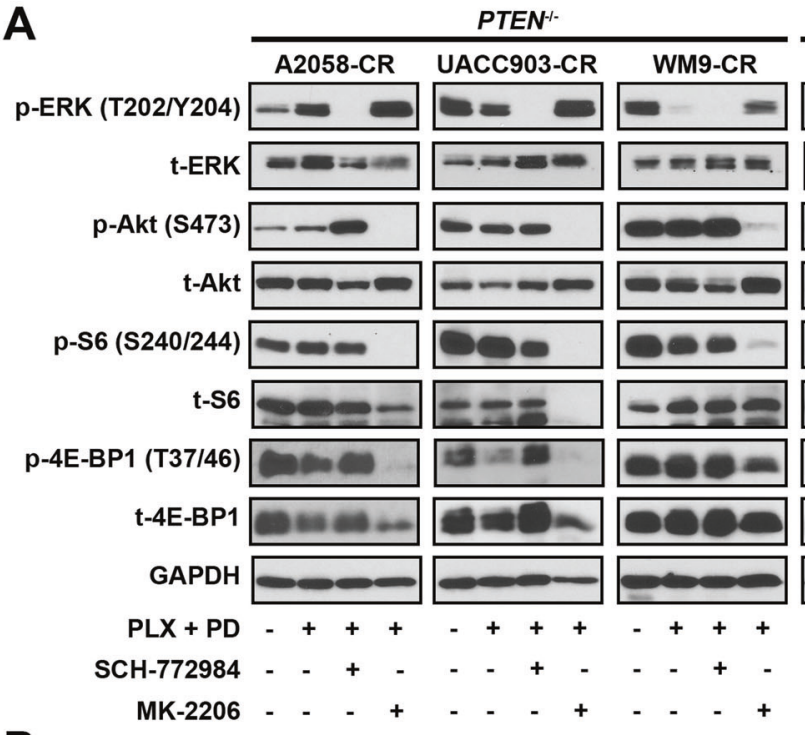

PTEN $^{+1-}$

1205Lu-CR A375-CR WM164-CR kDa

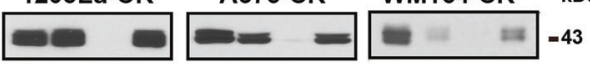
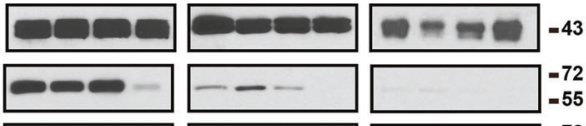

$-\infty-6$
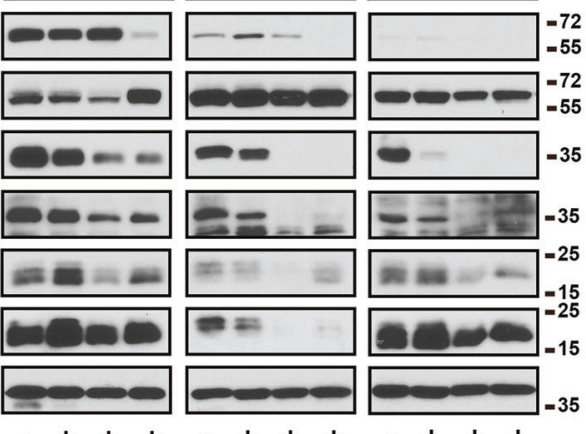

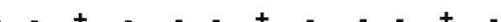

PLX + PD PLX + PD

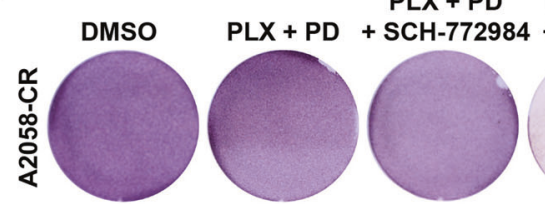

+ MK-2206

온
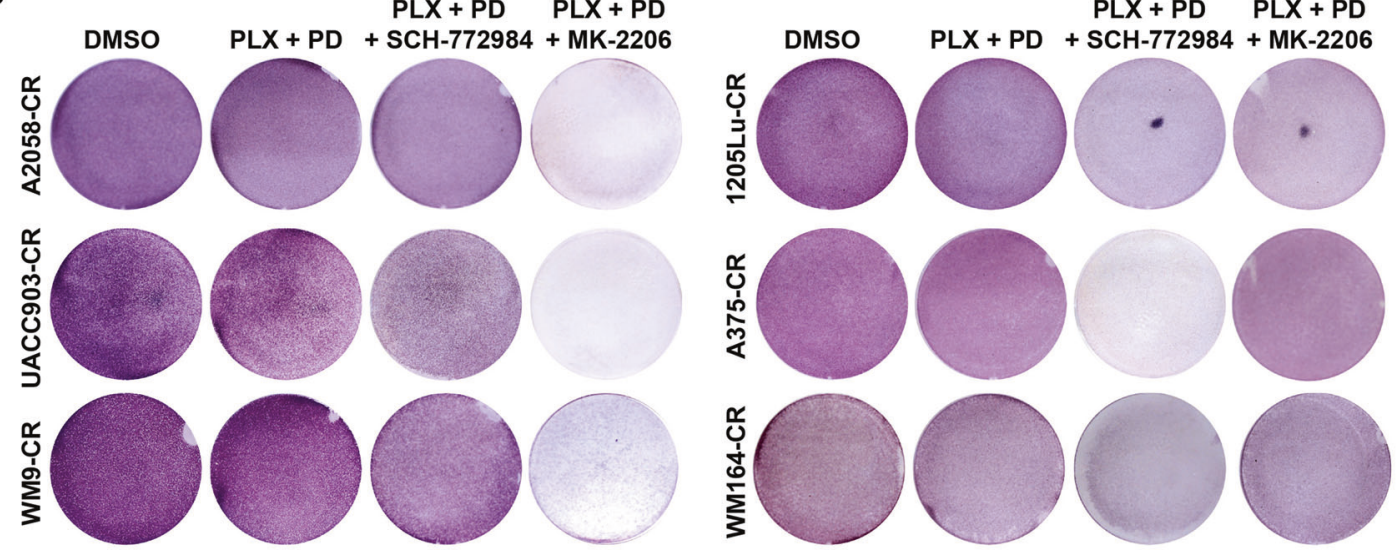

C
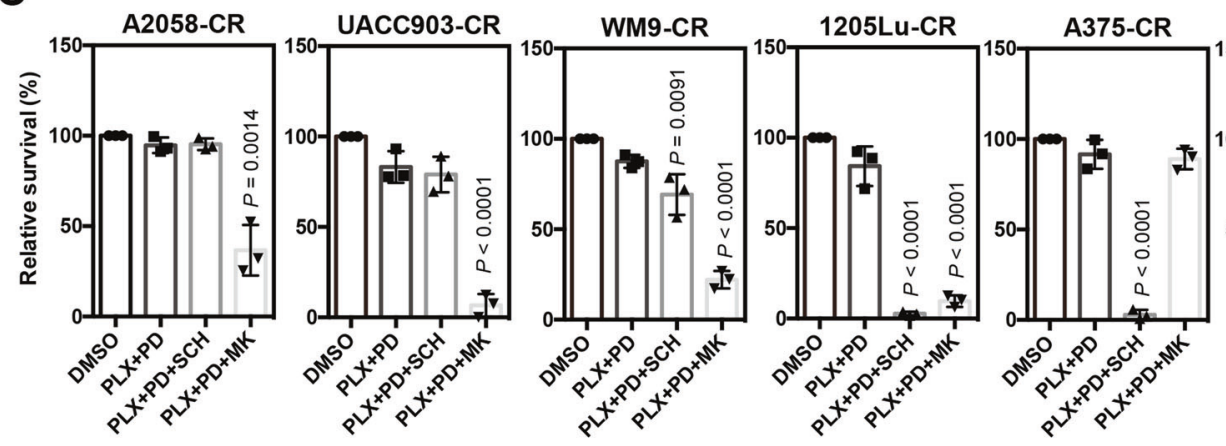

WM164-CR

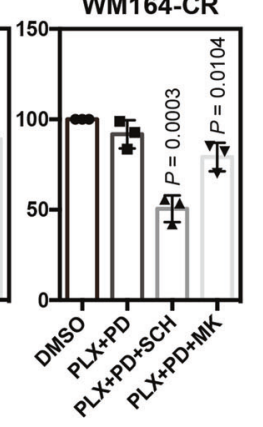

Fig. 5 mTORC1 activity in CR melanoma cells is regulated by ERK and AKT pathway. A The activation status of mTORC1 pathway in melanoma CR cells with indicated treatment. SCH-772984 and MK-2206 were used to inhibit the activation of ERK and AKT, respectively. PTEN $^{-1-}$ represents cell lines with homozygous PTEN loss; PTEN ${ }^{+/-}$for cells with heterozygous PTEN loss; PTEN ${ }^{+/+}$for cells with wild-type PTEN. B Crystal violet assay of CR cells treated with SCH-772984 or MK-2206 in the presence of PLX-4720 and PD0325901. C Quantification of the crystal violet staining in (B). Data are presented as mean \pm SD $(n=3)$. P values (vs. PLX + PD treatment group) are from a two-sided unpaired Student's $t$-test.

Previous studies suggested that co-targeting the AKT/mTOR pathway reversed the resistance of some melanoma cell lines with intrinsic cross-resistance to BRAF and MEK inhibitors [43, 44, 64]. These studies suggest that, regardless of the mechanism of resistance (i.e. MAPK activation or AKT activation), addition of mTOR inhibitor could be an effective way to restore their sensitivity to BRAF or MEK inhibitors. Our results provide evidence that mTOR inhibitor in combination with BRAF and MEK inhibitors blocked the growth of CR melanoma cells primarily due to cell cycle arrest. Targeting elF4F and S6, two critical mTORC1 downstream proteins, has also been shown to be an effective approach to overcoming drug resistance of melanoma to MAPK inhibitors $[63,65,66]$. Moreover, in a previous clinical study, dual inhibition of mTOR and MAPK signaling pathways doubled the progression-free survival benefit relative to monotherapy (ClinicalTrials.gov identifier: NCT01390818). A recent Phase I clinical 


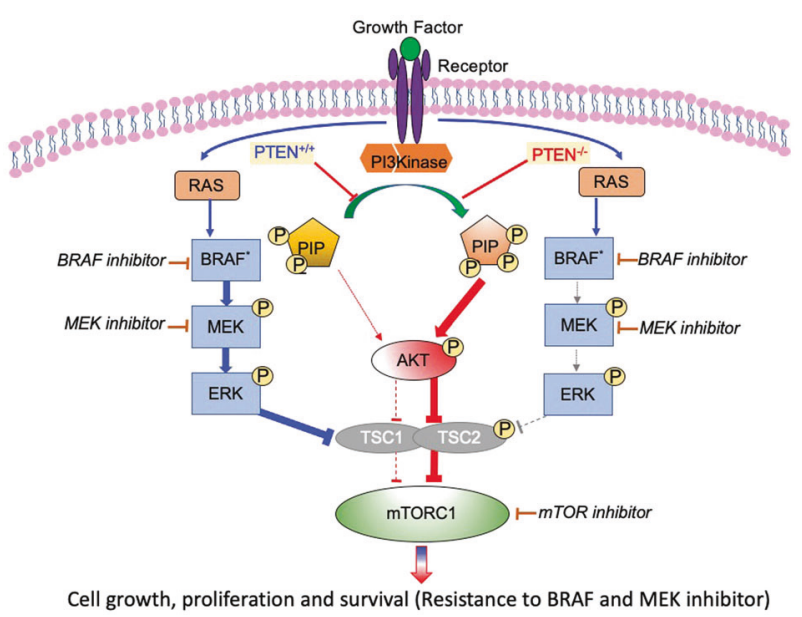

Fig. 6 Schematic diagram showing the contribution of MAPK signaling and PI3K/AKT signaling in CR melanoma cells. For CR melanoma with wild-type PTEN, MAPK signaling plays an important role in mTORC1 activity restoration. For CR melanoma with PTEN loss, mTOR signaling restoration relies on the PI3K/AKT activation. See text for details.

study also showed that the combination of BRAF inhibitor (vemurafenib) with rapamycin (everolimus, rapamycin analogs) is safe and well tolerated, with partial responses among different cancers, including patients who previously experienced progression on BRAF and/or MEK inhibitor therapy [67]. However, it was also reported that inhibition of $\mathrm{mTORC} 1$ by rapamycin and its analogues resulted in hyperactivation of AKT through the release of S6K1 and IRS-1 negative feedback loop [68]. This could be a concern for the use rapamycin. Deng et al. reported rapamycin needed to be combined with PI3K inhibitor to induce more cell death in de novo resistant cell lines to BRAFi [53]. Shi et al. demonstrated that $\mathrm{PI} 3 \mathrm{~K}$ and mTORC1/2 inhibition should be combined with BRAF or MEK inhibitor for higher inhibitory response in BRAFi resistant cell lines because rapamycin caused compensatory survival signaling even with simultaneous inhibition of MEK and/or AKT [9]. Gopal et al. also showed that inhibition of AKT, mTOR1/2, or insulin-like growth factor I receptor resulted in higher synergistic cell killing of melanoma cell with de novo resistance to MEKi than rapamycin [51]. On the other hand, while dual PI3K and mTOR inhibitor showed improved efficacy in inhibiting tumor growth in preclinical models, adverse effects and poor tolerability were also reported for pancreatic neuroendocrine tumors patients [69-73].

To determine the molecular mechanism for the restoration of mTORC1 activity, we evaluated the activation status of ERK and PI3K/AKT pathways in CR melanoma cells. Reactivation of the MAPK pathway has been proposed to be a major mechanism underlying the resistance of melanoma cells to BRAFi [74], and the combination of BRAF and MEK inhibition [75]. Previous studies have demonstrated that resistant melanoma cells displayed activated ERK due to a MEK2 mutation and BRAF amplification, which contributed to sustained mTOR activity in resistant cells $[61,62]$. Our data suggest that ERK activation was important for the recovery of mTORC1 activity only in a subset of CR melanoma cell lines that express wild-type PTEN, where the RAS/ERK pathway is a major regulator of mTORC1. On the other hand, AKT inhibition decreased mTORC1 activity in all the CR melanoma cells lines tested, suggesting that AKT is upstream of mTORC1 activity in cells with mutant or wild-type PTEN. These results are consistent with the findings that the activation of PI3K/AKT pathway is crucial in the acquisition of drug resistance in melanoma [74, 76, 77]. Silva et al. reported that MAPK inhibition was able to inhibit mTORC1 activity in treatment-naive BRAF-mutant melanoma cells, while
AKT inhibition failed to suppress this activity [78]. Based on our results, we propose that activation of mTORC1 activity shifts from ERK to the PI3K/AKT pathway in CR melanoma cells, and that upstream activation of mTORC 1 activity in these melanoma cells is closely associated with PTEN status. These data are in agreement with the earlier reports demonstrating PTEN genetic status was associated with intrinsic and acquired drug resistance in melanoma cells $[76,79,80]$. We show that mTOR inhibition is generally effective in decreasing the survival of CR cells, with $C R$ cells with PTEN loss having higher sensitivity to mTOR inhibitor (Fig. 3F; Fig. S2A, B). Previous studies showed receptor tyrosine kinase (RTK) upregulation and activation contributed to the resistance to BRAFi or MEKi $[10,42,51]$, which may also involve the restoration of $\mathrm{mTORC} 1$ activity through the PI3K/AKT and MAPK pathways. However, the exact mechanism of RTKs for mTOR activation in different CR melanoma situation needs further indepth study.

In summary, our study demonstrates that the restoration of mTORC1 activity is important in mediating acquired resistance of BRAF-mutant melanoma to MAPK inhibitors. While future studies are needed to understand the upstream signaling events such as RTK upregulation and NRAS mutations in mTOR activation, our study warrants further evaluation of $\mathrm{PI} 3 \mathrm{~K} / \mathrm{mTOR}$ inhibitors to overcome resistance to combined BRAF/MEK inhibitors. Furthermore, PTEN status should be considered in CR melanoma patients when selecting appropriate second line therapies.

\section{MATERIALS AND METHODS}

\section{Cell lines, reagents, and antibodies}

Human metastatic melanoma cell lines were established at the Wistar Institute as previously described [17]. They were authenticated by DNA fingerprinting and were tested regularly before assays to avoid mycoplasma contamination. Melanoma cells were cultured in RPMI 1640 (Invitrogen) supplemented with 5\% FBS (Gibco). The resistant cells that acquired resistance to PLX-4720 $(10 \mu \mathrm{M})$ and PD0325901 (1 $\mu \mathrm{M})$ combination were established after continuous treatment, and the CR cells were maintained with the combination of PLX-4720 at $2.5 \mu \mathrm{M}$ and PD0325901 at $0.25 \mu \mathrm{M}$ throughout the experiments. PLX-4720. SCH-772984 and MK-2206 were purchased from Selleck, Inc. PD0325901, rapamycin (Rapa), NVPBEZ235 (BEZ) were purchased from LC Laboratories. All information about the primary antibodies is included in Table S1. Secondary antibodies were purchased from Cell Signaling Technology (CST).

\section{Cell viability, proliferation, cell cycle, and apoptosis assays}

Cell viability was assayed by crystal violet staining. Briefly, equal amounts of cells were seeded in six-well plates at $60 \%$ confluence overnight and then treated with DMSO or specific inhibitors (PLX + PD: $2.5+0.25 \mu \mathrm{M}$; Rapamycin (Rapa): $100 \mathrm{nM}$; NVP-BEZ235 (BEZ): $1 \mu \mathrm{M}$; SCH-772984: $2 \mu \mathrm{M}$ and MK-2206: $1 \mu \mathrm{M}$ ) for 3 days. The cells were then washed with PBS and fixed with glutaraldehyde solution $(500 \mu \mathrm{l}$ glutardialdehyde in $12.5 \mathrm{ml} \mathrm{PBS}$, $\mathrm{pH}$ 7.4) for $20 \mathrm{~min}$. After rinsing with PBS, cells were stained with $0.02 \%$ crystal violet solution for $30 \mathrm{~min}$. After extensive washing with distilled water, cells were air-dried.

Cell number and growth were measured by MTT assays using the Cell Proliferation Kit I (Roche) according to the manufacturer's instruction. The cells were seeded into the 96 -well plate at a density of 5000 cells/well overnight, followed by treatment with serial dilution of drugs for $72 \mathrm{~h}$. The maximum concentration for the indicated drugs as followed: Rapa, $100 \mu \mathrm{M}$; BEZ, $100 \mu \mathrm{M}$; PLX-4720 (PLX, $100 \mu \mathrm{M})$ and PD0325901 (PD, $10 \mu \mathrm{M})$. The dilution ratio is 1:10. At least three independent experiments were performed. The IC50 values were calculated from dose-response curves using GraphPad Prism 6.0.

For 5-ethynyl-2'-deoxyuridine (EdU) cell proliferation assay (Ribo-Bio Co., Ltd., Guangzhou, China), CR cells were seeded on cover slips at a density of $1 \times 10^{5}$ cells $/ \mathrm{ml}$ overnight. The attached cells were processed for the indicated treatments for $24 \mathrm{~h}$. All the inhibitors used in the treatments are listed as followed: Rapa, $100 \mathrm{nM} ; \mathrm{BEZ}, 1 \mu \mathrm{M}$; PLX, $2.5 \mu \mathrm{M}$ and PD, $0.25 \mu \mathrm{M}$. $2 \mathrm{~h}$ before collection, $100 \mu \mathrm{L}$ EdU solution $(50 \mu \mathrm{M})$ was added into the medium. The collected cells were fixed in $4 \%$ paraformaldehyde for $20 \mathrm{~min}$ and subsequently permeabilized with PBS containing $0.5 \%$ Triton X-100 for 
$20 \mathrm{~min}$. The cells were then stained with $100 \mu \mathrm{L} 1 \times$ Apollo $^{\oplus}$ stain liquid at room temperature away from light for $30 \mathrm{~min}$, followed by DAPI staining for $5 \mathrm{~min}$. After washing with PBS, the cells were mounted and examined under a fluorescence microscope. The percentage of EdU-positive cells was calculated from five random fields in three wells.

Apoptosis was determined by Annexin-V APC/7-Aminoactinomycin D (7AAD) double-staining. After treated with Rapa, $100 \mathrm{nM}, \mathrm{BEZ}, 1 \mu \mathrm{M}$ in the presence of PLX, $2.5 \mu \mathrm{M}$ and PD, $0.25 \mu \mathrm{M}$ for $72 \mathrm{~h}, \mathrm{CR}$ cells were collected and washed twice with cold cell staining buffer (Biolegend, San Diego, CA). Then $5 \mu \mathrm{l}$ FITC Annexin-V staining solution (Biolegend) were mixed with cells at a concentration of $1 \times 10^{6}$ cells $/ \mathrm{ml}$, and kept in dark on ice for $15 \mathrm{~min} .5 \mu \mathrm{l}$ 7-AAD solution was added and incubated at room temperature for 5 min. Subsequently, with $400 \mu \mathrm{l}$ Annexin $\mathrm{V}$ binding buffer added to each cell suspension, the cells were immediately analyzed using a BD LSRII flow cytometer, the results of which were analyzed using FlowJo software (TreeStar Inc.).

For cell cycle analysis, after treatment with Rapa, $100 \mathrm{nM}, \mathrm{BEZ}, 1 \mu \mathrm{M}$ in the presence of PLX, $2.5 \mu \mathrm{M}$ and PD, $0.25 \mu \mathrm{M}$ for $24 \mathrm{~h}, \mathrm{CR}$ cells were harvested and fixed with ice-cold $70 \%$ ethanol for at least $2 \mathrm{~h}$ at $4{ }^{\circ} \mathrm{C}$. Ethanol was added dropwise to the cell pellet while vertexing. Cells were then treated with DNase-free RNase $(200 \mu \mathrm{g} / \mathrm{ml})$ for at least $2 \mathrm{~h}$. After centrifugation, cells were resuspended in propidium iodide solution $(20 \mu \mathrm{g} / \mathrm{ml})$ for $30 \mathrm{~min}$ at room temperature in dark and subsequently analyzed using a FACS Calibur. The analysis for cell cycle was performed as previously described [17].

\section{Western blot analysis}

Cell lysates were prepared in RIPA buffer supplemented with protease and phosphatase inhibitor cocktail (Roche) $24 \mathrm{~h}$ after the different drug treatments. After centrifugation at $16,000 \mathrm{~g}$ for $30 \mathrm{~min}$ at $4{ }^{\circ} \mathrm{C}$, protein concentration was determined by Bradford assays (Bio-Rad). Equal amounts of protein were loaded and separated by sodium dodecyl sulfate polyacrylamide gel electrophoresis, and transferred onto nitrocellulose membranes. After blocking with 5\% nonfat milk at room temperature for $1 \mathrm{~h}$, the diluted primary antibody was utilized to incubate with the nitrocellulose membranes at $4{ }^{\circ} \mathrm{C}$ overnight. The immunoactivity was detected with horseradish peroxidase-conjugated secondary antibodies (anti-mouse and anti-rabbit, both from CST). Subsequently, the blots were developed with ECL Western Blotting Substrate (Pierce). Information about the primary antibody is listed in Table S1.

\section{Immunohistochemistry (IHC)}

IHC was performed on formalin-fixed, paraffin-embedded sections. Briefly, after deparaffinization, antigens were retrieved by steaming the tissue section in citrate buffer $(10 \mathrm{mmol} / \mathrm{L}, \mathrm{pH} 6.0)$ and Tris-EDTA buffer $(\mathrm{pH} 9.0)$ for $5 \mathrm{~min}$. After blocking with Protein Block Serum-Free (Dako, Agilent), sections were incubated with the primary antibody overnight at $4{ }^{\circ} \mathrm{C}$. Following incubation with a biotinylated secondary antibody (1:200) for $30 \mathrm{~min}$, the peroxidase activity of sections was visualized with Fast Red or DAB (Vector) and counter-stained with Hematoxylin (Life technologies). Five areas containing the highest numbers of stained cells within each section were selected for histologic quantification under the light microscopy at $\times 400$ magnification. For calculating $\mathrm{H}$-score, a semiquantitative approach was used as previously described [81-83]. The pathologist who examined the tumor sections was blinded to the treatment information. All the primary antibody information has been listed in Table S1.

\section{Patient specimen collection and generation of patient-derived xenograft (PDX)}

Clinical data and tissue collection from patients with Stage IV melanoma was performed with informed consent at the University of Pennsylvania Abramson Cancer Center in accordance with the Institutional Review Board (Protocol number 707906). PDX tumors derived from patients with metastatic melanoma who progressed on the combined targeted therapies were expanded in vivo using NOD/SCID/LL-2R ${ }^{-1-}$ (NSG) mice before the therapy experiments as previously described [84, 85]. The expansion phase was under continuous drug pressure at approximately clinical plasma levels.

\section{Animal studies}

All animal experiments were reviewed and approved by Institutional Animal Care and Use Committee (IACUC) of the University of Pennsylvania and the Wistar Institute. For the establishment of drugresistant melanoma xenograft models, a suspension of A2058-CR or
UACC903-CR cells $\left(5 \times 10^{6}\right.$ cells $\left./ 100 \mu \mathrm{l}\right)$ was inoculated into the flanks of 8 -week old female athymic nu/nu mice. Each group has 5 mice, which is determined based on the studies in the similar field. Tumor size was measured by a digital caliper and the volume was calculated by the formula: length $\times(\text { width })^{2} / 2$. When the tumor volume reached $\sim 100 \mathrm{~mm}^{3}$, mice were then allocated randomly to different treatment groups. All the CR xenografts had been fed with chow containing Dabrafenib $(150 \mathrm{mg} / \mathrm{kg})$ and Trametinib $(1.5 \mathrm{mg} / \mathrm{kg})$ (Bio-Serv). Mice bearing the established A2058-CR or UACC903-CR xenograft were treated with PLX-4720 (200 p.p.m.) and PD0325901 (7 p.p.m.) individually or in combination with rapamycin $(12.5 \mathrm{mg} / \mathrm{kg})$ by oral gavage twice daily. For the control group, the matching xenografts were administrated with an equal amount of vehicle. Mice were euthanized before the tumor reached $10 \%$ of the body weight or the longest tumor dimension reached $2.0 \mathrm{~cm}$. The health status of the mice was monitored during the course of the experiment in case of signs of distress. The mice were euthanized once determined to have poor health condition score according to IACUC policy. No specific blinding technique was used for the animal studies.

\section{RPPA}

The analysis of RPPA data was performed according to the protocol from the M.D. Anderson Cancer Center [86]. Specifically, relative protein levels for each sample were determined by interpolation of each dilution curves from the "standard curve" (supercurve) of the slide (antibody). Supercurve is constructed by a script in R written by the RPPA core facility. These values are defined as Supercurve Log2 value. All the data points were normalized for protein loading and transformed to linear value, designated as "Normalized Linear", which was transformed to Log2 value, and then median-centered for further analysis. Median-Centered values were centered by 31 subtracting the median of all samples in a given protein. All of the above-mentioned procedures were performed by the RPPA core facility. Pathway scores were calculated according to a previous publication [87]. The pathway predictors used to calculate each pathway score had been listed in Table S2. The normalized data provided were visualized using MORPHEUS (https://software.broadinstitute.org/morpheus/).

\section{Statistical analysis}

Statistical analyses were performed using GraphPad Prism 6.0. Sample sizes were determined based on the studies we and other researchers published. Normality of distribution was determined by D'AgostinoPearson omnibus normality test and the equal variance assumption among groups was assessed by Brown-Forsythe test. One-way ANOVA was used to compare mouse tumor volume data among different groups. Twosided Student's $t$-tests were used for pair-wise comparison of the remaining datasets. Data are represented as mean \pm SD. A two-tailed value of $P<0.05$ was considered statistically significant.

\section{REFERENCES}

1. Siegel R, Ma J, Zou Z, Jemal A. Cancer statistics, 2014. CA Cancer J Clin. 2014;64:9-29.

2. Menzies AM, Long GV. Systemic treatment for BRAF-mutant melanoma: where do we go next? Lancet Oncol. 2014;15:e371-381.

3. Davies H, Bignell GR, Cox C, Stephens P, Edkins S, Clegg S, et al. Mutations of the BRAF gene in human cancer. Nature. 2002;417:949-54.

4. Long GV, Hauschild A, Santinami M, Atkinson V, Mandala M, Chiarion-Sileni V, et al. Adjuvant Dabrafenib plus Trametinib in Stage III BRAF-Mutated Melanoma. N. Engl J Med. 2017;377:1813-23.

5. Rizos H, Menzies AM, Pupo GM, Carlino MS, Fung C, Hyman J, et al. BRAF inhibitor resistance mechanisms in metastatic melanoma: spectrum and clinical impact. Clin Cancer Res. 2014;20:1965-77.

6. Wagle N, Emery C, Berger MF, Davis MJ, Sawyer A, Pochanard P, et al. Dissecting therapeutic resistance to RAF inhibition in melanoma by tumor genomic profiling. J Clin Oncol. 2011;29:3085-96.

7. Corcoran RB, Dias-Santagata D, Bergethon K, lafrate AJ, Settleman J, Engelman JA. BRAF gene amplification can promote acquired resistance to MEK inhibitors in cancer cells harboring the BRAF V600E mutation. Sci Signal. 2010;3:ra84.

8. Emery CM, Vijayendran KG, Zipser MC, Sawyer AM, Niu L, Kim JJ, et al. MEK1 mutations confer resistance to MEK and B-RAF inhibition. Proc Natl Acad Sci USA. 2009;106:20411-6.

9. Shi H, Kong X, Ribas A, Lo RS. Combinatorial treatments that overcome PDGFRbeta-driven resistance of melanoma cells to V600EB-RAF inhibition. Cancer Res. 2011;71:5067-74. 
10. Nazarian R, Shi H, Wang Q, Kong X, Koya RC, Lee H, et al. Melanomas acquire resistance to B-RAF(V600E) inhibition by RTK or N-RAS upregulation. Nature. 2010;468:973-7.

11. Long GV, Fung C, Menzies AM, Pupo GM, Carlino MS, Hyman J, et al. Increased MAPK reactivation in early resistance to dabrafenib/trametinib combination therapy of BRAF-mutant metastatic melanoma. Nat Commun. 2014;5:5694.

12. Wagle N, Van Allen EM, Treacy DJ, Frederick DT, Cooper ZA, Taylor-Weiner A, et al. MAP kinase pathway alterations in BRAF-mutant melanoma patients with acquired resistance to combined RAF/MEK inhibition. Cancer Discov. 2014;4:61-68.

13. Corcoran RB, Settleman J, Engelman JA. Potential therapeutic strategies to overcome acquired resistance to BRAF or MEK inhibitors in BRAF mutant cancers. Oncotarget. 2011;2:336-46.

14. Yao Z, Torres NM, Tao A, Gao Y, Luo L, Li Q, et al. BRAF mutants evade ERKdependent feedback by different mechanisms that Ddetermine their sensitivity to pharmacologic inhibition. Cancer Cell. 2015;28:370-83.

15. Moriceau G, Hugo W, Hong A, Shi H, Kong X, Yu CC, et al. Tunable-combinatorial mechanisms of acquired resistance limit the efficacy of BRAF/MEK cotargeting but result in melanoma drug addiction. Cancer Cell. 2015;27:240-56.

16. Solit DB, Garraway LA, Pratilas CA, Sawai A, Getz G, Basso A, et al. BRAF mutation predicts sensitivity to MEK inhibition. Nature. 2006;439:358-62.

17. Lu H, Liu S, Zhang G, Bin W, Zhu Y, Frederick DT, et al. PAK signalling drives acquired drug resistance to MAPK inhibitors in BRAF-mutant melanomas. Nature. 2017;550:133-6.

18. Hu-Lieskovan S, Mok S, Homet Moreno B, Tsoi J, Robert L, Goedert L, et al. Improved antitumor activity of immunotherapy with BRAF and MEK inhibitors in BRAF(V600E) melanoma. Sci Transl Med. 2015;7:279ra241.

19. Iadevaia V, Huo Y, Zhang Z, Foster LJ, Proud CG. Roles of the mammalian target of rapamycin, $\mathrm{mTOR}$, in controlling ribosome biogenesis and protein synthesis. Biochem Soc Trans. 2012;40:168-72.

20. Ben-Sahra I, Manning BD. mTORC1 signaling and the metabolic control of cell growth. Curr Opin Cell Biol. 2017;45:72-82.

21. Laplante M, Sabatini DM. mTOR signaling at a glance. J Cell Sci. 2009;122:3589-94.

22. Ma XM, Blenis J. Molecular mechanisms of mTOR-mediated translational control. Nat Rev Mol Cell Biol. 2009;10:307-18.

23. Schieke SM, Phillips D, McCoy JP Jr., Aponte AM, Shen RF, Balaban RS, et al. The mammalian target of rapamycin (mTOR) pathway regulates mitochondrial oxygen consumption and oxidative capacity. J Biol Chem. 2006;281:27643-52.

24. Laplante M, Sabatini DM. An emerging role of mTOR in lipid biosynthesis. Curr Biol. 2009;19:R1046-1052.

25. Sarbassov DD, Ali SM, Kim DH, Guertin DA, Latek RR, Erdjument-Bromage $H$, et al. Rictor, a novel binding partner of mTOR, defines a rapamycin-insensitive and raptor-independent pathway that regulates the cytoskeleton. Curr Biol. 2004; 14:1296-302.

26. Kim LC, Cook RS, Chen J. mTORC1 and mTORC2 in cancer and the tumor microenvironment. Oncogene. 2017;36:2191-201.

27. Jacinto $E$, Loewith $R$, Schmidt A, Lin S, Ruegg MA, Hall A, et al. Mammalian TOR complex 2 controls the actin cytoskeleton and is rapamycin insensitive. Nat Cell Biol. 2004;6:1122-8.

28. Populo $H$, Lopes JM, Soares $P$. The mTOR signalling pathway in human cancer. Int J Mol Sci. 2012;13:1886-918.

29. Guertin DA, Sabatini DM. Defining the role of mTOR in cancer. Cancer Cell. 2007;12:9-22.

30. Saxton RA, Sabatini DM. mTOR signaling in growth, metabolism, and disease. Cell. 2017;168:960-76.

31. Inoki K, Corradetti MN, Guan KL. Dysregulation of the TSC-mTOR pathway in human disease. Nat Genet. 2005;37:19-24.

32. Meric-Bernstam F, Gonzalez-Angulo AM. Targeting the mTOR signaling network for cancer therapy. J Clin Oncol. 2009;27:2278-87.

33. Efeyan A, Sabatini DM. mTOR and cancer: many loops in one pathway. Curr Opin Cell Biol. 2010;22:169-76.

34. Inoki K, Li Y, Zhu T, Wu J, Guan KL. TSC2 is phosphorylated and inhibited by Akt and suppresses mTOR signalling. Nat Cell Biol. 2002;4:648-57.

35. Hay N. The Akt-mTOR tango and its relevance to cancer. Cancer Cell. 2005;8:179-83.

36. Shaw RJ, Cantley LC. Ras, $\mathrm{PI}(3) \mathrm{K}$ and mTOR signalling controls tumour cell growth. Nature. 2006:441:424-30.

37. Porta C, Paglino C, Mosca A. Targeting PI3K/Akt/mTOR signaling in cancer. Front Oncol. 2014;4:64

38. Edinger AL, Thompson CB. Akt maintains cell size and survival by increasing mTOR-dependent nutrient uptake. Mol Biol Cell. 2002;13:2276-88.

39. Mendoza MC, Er EE, Blenis J. The Ras-ERK and PI3K-mTOR pathways: cross-talk and compensation. Trends Biochem Sci. 2011;36:320-8.
40. Corcoran RB, Rothenberg SM, Hata AN, Faber AC, Piris A, Nazarian RM, et al. TORC1 suppression predicts responsiveness to RAF and MEK inhibition in BRAFmutant melanoma. Sci Transl Med. 2013;5:196ra198.

41. Shi H, Hong A, Kong X, Koya RC, Song C, Moriceau G, et al. A novel AKT1 mutant amplifies an adaptive melanoma response to BRAF inhibition. Cancer Discov. 2014:4:69-79.

42. Villanueva J, Vultur A, Lee JT, Somasundaram R, Fukunaga-Kalabis M, Cipolla AK, et al. Acquired resistance to BRAF inhibitors mediated by a RAF kinase switch in melanoma can be overcome by cotargeting MEK and IGF-1R/PI3K. Cancer Cell. 2010;18:683-95.

43. Atefi M, von Euw E, Attar N, Ng C, Chu C, Guo D, et al. Reversing melanoma crossresistance to BRAF and MEK inhibitors by co-targeting the AKT/mTOR pathway. PLoS One. 2011;6:e28973.

44. Sweetlove M, Wrightson E, Kolekar S, Rewcastle GW, Baguley BC, Shepherd PR, et al. Inhibitors of pan-PI3K signaling synergize with BRAF or MEK inhibitors to prevent BRAF-mutant melanoma cell growth. Front Oncol. 2015;5:135.

45. El Zaoui I, Bucher M, Rimoldi D, Nicolas M, Kaya G, Pescini Gobert R, et al. Conjunctival melanoma targeted therapy: MAPK and PI3K/mTOR pathways inhibition. Investig Ophthalmol Vis Sci. 2019;60:2764-72.

46. Paraiso KH, Xiang Y, Rebecca VW, Abel EV, Chen YA, Munko AC, et al. PTEN loss confers BRAF inhibitor resistance to melanoma cells through the suppression of BIM expression. Cancer Res. 2011;71:2750-60.

47. Van Allen EM, Wagle N, Sucker A, Treacy DJ, Johannessen CM, Goetz EM, et al. The genetic landscape of clinical resistance to RAF inhibition in metastatic melanoma. Cancer Discov. 2014;4:94-109.

48. Xie X, White EP, Mehnert JM. Coordinate autophagy and mTOR pathway inhibition enhances cell death in melanoma. PLoS One. 2013;8:e55096.

49. Kappelmann-Fenzl M, Gebhard C, Matthies AO, Kuphal S, Rehli M, Bosserhoff AK. C-Jun drives melanoma progression in PTEN wild type melanoma cells. Cell Death Dis. 2019;10:584.

50. Rojo F, Najera L, Lirola J, Jimenez J, Guzman M, Sabadell MD, et al. 4E-binding protein 1 , a cell signaling hallmark in breast cancer that correlates with pathologic grade and prognosis. Clin Cancer Res. 2007;13:81-89.

51. Gopal YN, Deng W, Woodman SE, Komurov K, Ram P, Smith PD, et al. Basal and treatment-induced activation of AKT mediates resistance to cell death by AZD6244 (ARRY-142886) in Braf-mutant human cutaneous melanoma cells. Cancer Res. 2010;70:8736-47.

52. Serra V, Markman B, Scaltriti M, Eichhorn PJ, Valero V, Guzman M, et al. NVP$\mathrm{BEZ235}$, a dual $\mathrm{PI} 3 \mathrm{~K} / \mathrm{mTOR}$ inhibitor, prevents $\mathrm{PI} 3 \mathrm{~K}$ signaling and inhibits the growth of cancer cells with activating PI3K mutations. Cancer Res. 2008;68:8022-30.

53. Deng W, Gopal YN, Scott A, Chen G, Woodman SE, Davies MA. Role and therapeutic potential of PI3K-mTOR signaling in de novo resistance to BRAF inhibition. Pigment Cell Melanoma Res. 2012;25:248-58.

54. Penna I, Molla A, Grazia G, Cleris L, Nicolini G, Perrone F, et al. Primary crossresistance to BRAFV600E-, MEK1/2- and PI3K/mTOR-specific inhibitors in BRAFmutant melanoma cells counteracted by dual pathway blockade. Oncotarget. 2016;7:3947-65.

55. Long GV, Stroyakovskiy D, Gogas H, Levchenko E, de Braud F, Larkin J, et al. Combined BRAF and MEK inhibition versus BRAF inhibition alone in melanoma. N. Engl J Med. 2014;371:1877-88.

56. Sun C, Wang L, Huang S, Heynen GJ, Prahallad A, Robert C, et al. Reversible and adaptive resistance to $\operatorname{BRAF(V600E)~inhibition~in~melanoma.~Nature.~}$ 2014;508:118-22.

57. Larkin J, Ascierto PA, Dreno B, Atkinson V, Liszkay G, Maio M, et al. Combined vemurafenib and cobimetinib in BRAF-mutated melanoma. N. Engl J Med. 2014:371:1867-76.

58. Ali M, Bukhari SA, Ali M, Lee HW. Upstream signalling of mTORC1 and its hyperactivation in type 2 diabetes (T2D). BMB Rep. 2017;50:601-9.

59. LoRusso PM. Inhibition of the PI3K/AKT/mTOR pathway in solid tumors. J Clin Oncol. 2016;34:3803-15.

60. Kwitkowski VE, Prowell TM, Ibrahim A, Farrell AT, Justice R, Mitchell SS, et al. FDA approval summary: temsirolimus as treatment for advanced renal cell carcinoma. Oncologist. 2010;15:428-35.

61. Greger JG, Eastman SD, Zhang V, Bleam MR, Hughes AM, Smitheman KN, et al. Combinations of BRAF, MEK, and $\mathrm{PI} 3 \mathrm{~K} / \mathrm{mTOR}$ inhibitors overcome acquired resistance to the BRAF inhibitor GSK2118436 dabrafenib, mediated by NRAS or MEK mutations. Mol Cancer Ther. 2012;11:909-20.

62. Villanueva J, Infante JR, Krepler C, Reyes-Uribe P, Samanta M, Chen HY, et al. Concurrent MEK2 mutation and BRAF amplification confer resistance to BRAF and MEK inhibitors in melanoma. Cell Rep. 2013:4:1090-9.

63. Teh JLF, Cheng PF, Purwin TJ, Nikbakht N, Patel P, Chervoneva I, et al. In vivo E2F reporting reveals efficacious schedules of MEK1/2-CDK4/6 targeting and mTORS6 resistance mechanisms. Cancer Discov. 2018;8:568-81. 
64. Gopal YN, Rizos H, Chen G, Deng W, Frederick DT, Cooper ZA, et al. Inhibition of mTORC1/2 overcomes resistance to MAPK pathway inhibitors mediated by PGC1alpha and oxidative phosphorylation in melanoma. Cancer Res. 2014;74:7037-47.

65. Boussemart L, Malka-Mahieu H, Girault I, Allard D, Hemmingsson O, Tomasic G, et al. elF4F is a nexus of resistance to anti-BRAF and anti-MEK cancer therapies. Nature. 2014;513:105-9.

66. Romano G, Chen PL, Song P, McQuade JL, Liang RJ, Liu M, et al. A preexisting rare PIK3CA(E545K) subpopulation confers clinical resistance to MEK plus CDK4/6 inhibition in NRAS Mmelanoma and is Dependent on S6K1 signaling. Cancer Discov. 2018;8:556-67.

67. Subbiah V, Sen S, Hess KR, Janku F, Hong DS, Khatua S, et al. Phase I Study of the BRAF Inhibitor Vemurafenib in Combination With the Mammalian Target of Rapamycin Inhibitor Everolimus in Patients With BRAF-Mutated Malignancies. JCO Precision Oncology. 2018;2:1-12.

68. Wan X, Harkavy B, Shen N, Grohar P, Helman L. Rapamycin induces feedback activation of Akt signaling through an IGF-1R-dependent mechanism. Oncogene. 2007;26:1932-40.

69. Carlo MI, Molina AM, Lakhman Y, Patil S, Woo K, DeLuca J, et al. A Phase lb Study of BEZ235, a Dual Inhibitor of Phosphatidylinositol 3-Kinase (PI3K) and Mammalian Target of Rapamycin (mTOR), in Patients With Advanced Renal Cell Carcinoma. Oncologist. 2016;21:787-8.

70. Fazio N, Buzzoni R, Baudin E, Antonuzzo L, Hubner RA, Lahner $\mathrm{H}$, et al. A Phase II Study of BEZ235 in Patients with Everolimus-resistant, Advanced Pancreatic Neuroendocrine Tumours. Anticancer Res. 2016;36:713-9.

71. Libutti S, Garcia-Carbonero R, Wolin EM, Custodio A, Yao JC, Hendifar AE, et al. CBEZ235Z2401: Randomized Phase II Study of BEZ235 or Everolimus (EVE) in Patients with Advanced Pancreatic Neuroendocrine Tumors (pNET). Neuroendocrinology. 2015;102:131-131.

72. Salazar R, Verslype C, Baudin E, Libutti SK, Yao JC, Buzzoni R, et al. Phase II studies of BEZ235 in patients with advanced pancreatic neuroendocrine tumors (pNET). J Clin Oncol. 2015;33:4102.

73. Pongas G, Fojo T. BEZ235: when promising science meets clinical reality. Oncologist. 2016;21:1033-4.

74. Welsh SJ, Rizos H, Scolyer RA, Long GV. Resistance to combination BRAF and MEK inhibition in metastatic melanoma: Where to next? Eur J Cancer. 2016;62:76-85.

75. Kwong LN, Boland GM, Frederick DT, Helms TL, Akid AT, Miller JP, et al. Co-clinical assessment identifies patterns of BRAF inhibitor resistance in melanoma. J Clin Investig. 2015;125:1459-70.

76. Shi H, Hugo W, Kong X, Hong A, Koya RC, Moriceau G, et al. Acquired resistance and clonal evolution in melanoma during BRAF inhibitor therapy. Cancer Discov. 2014;4:80-93.

77. Amaral T, Sinnberg T, Meier F, Krepler $C$, Levesque $M$, Niessner $H$, et al. MAPK pathway in melanoma part II-secondary and adaptive resistance mechanisms to BRAF inhibition. Eur J Cancer. 2017;73:93-101.

78. Silva JM, Bulman C, McMahon M. BRAFV600E cooperates with PI3K signaling, independent of $A K T$, to regulate melanoma cell proliferation. Mol Cancer Res. 2014;12:447-63.

79. Zuo Q, Liu J, Huang L, Qin Y, Hawley T, Seo C, et al. AXL/AKT axis mediatedresistance to BRAF inhibitor depends on PTEN status in melanoma. Oncogene. 2018;37:3275-89.

80. Wang J, Sinnberg T, Niessner H, Dolker R, Sauer B, Kempf WE, et al. PTEN regulates IGF-1R-mediated therapy resistance in melanoma. Pigment Cell Melanoma Res. 2015;28:572-89.

81. Hirsch FR, Varella-Garcia M, Bunn PA Jr., Di Maria MV, Veve R, Bremmes RM, et al. Epidermal growth factor receptor in non-small-cell lung carcinomas: correlation between gene copy number and protein expression and impact on prognosis. $J$ Clin Oncol. 2003;21:3798-807.

82. John T, Liu G, Tsao MS. Overview of molecular testing in non-small-cell lung cancer: mutational analysis, gene copy number, protein expression and other biomarkers of EGFR for the prediction of response to tyrosine kinase inhibitors. Oncogene. 2009;28:S14-23.

83. Kumar SM, Acs G, Fang D, Herlyn M, Elder DE, Xu X. Functional erythropoietin autocrine loop in melanoma. Am J Pathol. 2005;166:823-30.

84. Krepler C, Xiao M, Sproesser K, Brafford PA, Shannan B, Beqiri M, et al. Personalized preclinical trials in BRAF inhibitor-resistant patient-derived xenograft models identify second-line combination therapies. Clin Cancer Res. 2016;22:1592-602.

85. Krepler C, Sproesser K, Brafford P, Beqiri M, Garman B, Xiao M, et al. A comprehensive patient-derived xenograft collection representing the heterogeneity of melanoma. Cell Rep. 2017;21:1953-67.

86. Tibes R, Qiu Y, Lu Y, Hennessy B, Andreeff M, Mills GB, et al. Reverse phase protein array: validation of a novel proteomic technology and utility for analysis of primary leukemia specimens and hematopoietic stem cells. Mol Cancer Ther. 2006;5:2512-21.

87. Akbani R, Ng PK, Werner HM, Shahmoradgoli M, Zhang F, Ju Z, et al. A pan-cancer proteomic perspective on The Cancer Genome Atlas. Nat Commun. 2014;5:3887.

\section{ACKNOWLEDGEMENTS}

This work was supported by NIH R35GM141832, P01 CA114046, P50 CA174523, U54 CA224070, DoD PRCRP WX1XWH-16-1-0119 [CA150619], and a kind gift from the Dr. Miriam and Sheldon G. Adelson Medical Research Foundation to MH and GBM.

\section{COMPETING INTERESTS}

The authors declare no competing interests.

\section{ADDITIONAL INFORMATION}

Supplementary information The online version contains supplementary materia available at https://doi.org/10.1038/s41388-021-01911-5.

Correspondence and requests for materials should be addressed to M.H. or W.G.

Reprints and permission information is available at http://www.nature.com/ reprints

Publisher's note Springer Nature remains neutral with regard to jurisdictional claims in published maps and institutional affiliations.

Open Access This article is licensed under a Creative Commons Attribution 4.0 International License, which permits use, sharing, adaptation, distribution and reproduction in any medium or format, as long as you give appropriate credit to the original author(s) and the source, provide a link to the Creative Commons license, and indicate if changes were made. The images or other third party material in this article are included in the article's Creative Commons license, unless indicated otherwise in a credit line to the material. If material is not included in the article's Creative Commons license and your intended use is not permitted by statutory regulation or exceeds the permitted use, you will need to obtain permission directly from the copyright holder. To view a copy of this license, visit http://creativecommons. org/licenses/by/4.0/.

(c) The Author(s) 2021 